\title{
PERFORMANCE AND CAPACITY CALCULATION METHODS OF SELF-STRESSING STEEL SLAG CONCRETE FILLED STEEL TUBULAR SHORT COLUMNS SUBJECTED TO AXIAL LOAD
}

\author{
Yuan Fang ${ }^{1}$, Feng Yu ${ }^{1, *}$, Rui Bai ${ }^{2}$, Lin Xu ${ }^{1}$, Yuan-Di Qian ${ }^{1,3}$ and Guo-Sheng Xiang ${ }^{1}$ \\ ${ }^{\prime}$ Department of Civil Engineering and Architecture, Anhui University of Technology, Ma'anshan, China \\ ${ }^{2}$ Department of Civil and Environmental Engineering, The Hong Kong Polytechnic University, Hung Hom, Kowloon, Hong Kong, China \\ ${ }^{3}$ Technology center, China MCC17 Group Co., Ltd., Ma'anshan, 243000, Anhui, China \\ *(Corresponding author.Email: fyuan86@163.com)
}

\section{A B S T R A C T}

This paper experimentally investigates the mechanical performance of the self-stressing steel slag concrete filled steel tubular (SSSCFST) columns. Six short columns subjected to axial load are tested and the accuracy of different prescriptive methods is evaluated. The effect of the studied parameters, such as the expansion rate of steel slag concrete (SSC) $\left(E_{\mathrm{x}}\right)$ and diameter-thickness ratio of steel tube $(D / t)$, is considered. The failure modes are observed and the load-displacement curves of the specimens are obtained. The SSSCFST short columns with the low confinement effect coefficient under axial load are damaged by shear deformation, while the outward loca buckling dominates the failure of the axially loaded SSSCFST short columns with the high confinement effect coefficient. It is observed that the incremental range of the load capacity can be raised by enhancing the expansion rate of SSC. The ultimate load capacity and displacement of the columns decrease as the diameter-thickness ratio increases. Compared with the experimental results, the Hong Kong Code CoPHK (2011) and Australian Standard AS5100-2017 (2017) underestimate the ultimate load capacity of the axially loaded SSSCFST short columns. While, better predictions on the column strength can be achieved by the British Standard BS EN1994-2 (2005) and Chinese Specification DBJ/T13-51-2010 (2010). Additionally, a validated finite element (FE) model for the SSSCFST short columns is adopted to perform parametric studies to broaden the available experimental results about their behaviors.
ARTICLE H IST O RY

\begin{tabular}{ll}
\hline & \\
Received: & 13 July 2020 \\
Revised: & 5 November 2020 \\
Accepted: & 9 November 2020
\end{tabular}

\section{K E Y W O R D S}

Steel slag concrete;

Expansion rate;

Diameter-thickness ratio;

Failure modes;

Ultimate load capacity.

Copyright $(\odot) 2021$ by The Hong Kong Institute of Steel Construction. All rights reserved.

\section{Introduction}

Steel slag, the industrial by-product of steel-making, accounts for $15 \%$ to $20 \%$ of all steel production [1]. The annual output of steel slag was approximately 21 million tons in Europe, 14 million tons in Japan and over 100 million tons in China [2]. However, little steel slag was utilized. In China, over 400 million tons of the steel slag have been deposited leading to the problems in the resource waste, the lands occupation and the potential water and soil pollution. Therefore, dealing with these steel slags rationally and effectively has become an urgent issue. Recently, many scholars suggested to use the steel slags as the substitutes for concrete aggregates in civil engineering [3-4]. However, the volume instability of steel slags restricts its application. Theoretical and experimental studies on the volume stability of the steel slag concrete (SSC) have been extensively conducted and the some stabilizing measures have been developed, such as the SSC with the siliceous or fly ash [5-6], carbonization maintenance [7], and decreasing the content of $\mathrm{MgO}$ and $f-\mathrm{CaO}[8]$

Concrete filled steel tubular (CFST) columns, which have the high bearing capacity and good ductility, are convenient for the construction and have been extensively applied in civil engineering [9-10]. Nevertheless, the shrinkage crack of core concrete has a certain effect on the mechanical properties of CFST columns. To reduce the shrinkage, the SSSCFST column, which uses the SSC instead of the ordinary concrete as the filling material, is proposed for engineering structures. The slight expansion of the SSC can availably improve the mechanical properties of the composite columns and reduce the shrinking cracks. Yu et al. [11] conducted the tests on the compensated shrinking SSC and suggested the methods for calculating its ultimate stress, strain, Young's modulus and Poisson's ratio. Beggas et al. [12] investigated the thermal conductivity of the SSC and showed that the SSC could significantly enhance the thermal property of the SSC filled thin-wall steel tube structures. Zeghiche et al. [13] presented a non-linear FE model to study the performance of the cold formed steel tube filled with crystallized slag aggregate concrete. The effects of the section dimension, the infilled concrete and its age were investigated. Ferhoune et al. [14] examined the performance of the crushed crystallized slag concrete filled rectangular tube subjected to eccentric compression and confirmed that the load capacity was sensitive to the eccentric load and the length of stubs.

At present, numerous theoretical and experimental investigations on the SSC and CFST have been carried out and fruitful results have been achieved. However, few studies focus on the performance and design methods of the SSSCFST columns. In this study, the performance of the axially loaded SSSCFST short columns was experimentally investigated and six columns were designed and tested. The effects of the expansion rate of $\operatorname{SSC}\left(E_{\mathrm{x}}\right)$ and diameter-thickness ratio $(D / t)$ were analyzed. The results of load capacity of the columns calculated by the current CFST design provisions were compared with the experimental data, and the accuracy of the prescriptive methods for the design of the SSSCFST short columns was evaluated. In addition, a validated FE model for the axially loaded SSSCFST short columns was employed to conduct the parametric studies.

\section{Experimental program}

\subsection{Material properties}

In this study, all the seamless tubes were made of Q235 steel with the outer diameter of $140 \mathrm{~mm}$. Three types of steel tubes with thickness of 2.08 $\mathrm{mm}, 3.63 \mathrm{~mm}$ and $4.22 \mathrm{~mm}$ were used in the tests. By the method suggested in the Chinese code GB/T228.1-2010 [15], the corresponding average yield and ultimate strength of these three types of steel tubes were measured as 176.3MPa, 233.2MPa, 236.9MPa and 311.5MPa, 295.7MPa, 300.8MPa, respectively. The SSC was made of graded gravel (the particle size range was $5 \mathrm{~mm} \sim 31.5 \mathrm{~mm}$ ), steel slag, P. O 42.5 cement and water. The accumulation density of steel slag was $965 \mathrm{~kg} / \mathrm{m}^{3}$. The ratio between the components of the SSC, i.e., cement: water: graded gravel: steel slag, was 365:201:961:621.

Two different expansion rates of SSC, such as $E_{\mathrm{x}}=2.8 \times 10^{-4}, E_{\mathrm{x}}=-3.5 \times 10^{-4}$, were prepared. $E_{\mathrm{x}}$ is determined by the following formula.

$E_{\mathrm{xt}}=\left(L_{\mathrm{t}}-L_{0}\right) / L_{\mathrm{e}}$

In which, $E_{\mathrm{xt}}$ represents the $t$-th day expansion rate of SSC, $L_{\mathrm{e}}$ denotes the gauge length of SSC, $L_{0}$ stands for the length of SSC on the 3-th day, and $L_{\mathrm{t}}$ represents the length of SSC on the $t$-th day.

Different expansion rates of SSC were obtained by changing the particle sizes of steel slag. For the SSC with $E_{\mathrm{x}}=2.8 \times 10^{-4}$, the particle size range of steel slag was $1.18 \mathrm{~mm} \sim 2.36 \mathrm{~mm}$. For the SSC with $E_{\mathrm{x}}=-3.5 \times 10^{-4}$, the particle size range of steel slag was $0.15 \mathrm{~mm} \sim 0.6 \mathrm{~mm}$. Table 1 listed the components of the SSC and the corresponding strength measured according to Chinese Code GB50010-2010 [16]

\subsection{Specimens design and manufacture}

Two parameters, the expansion rate of SSC $E_{\mathrm{x}}$ and diameter-thickness ratio $D / t$ were studied in this analysis. Six specimens, including three SCA-1 
series short columns and three SCA-2 series short columns, subjected to axial load were carried out. The length of both series specimens was $500 \mathrm{~mm}$. The specific dimensions of the specimens were listed in Table 2.

The specimens were cut to the designed length from a long tube, and the end sections were polished and flatted. Two $300 \mathrm{~mm} \times 300 \mathrm{~mm} \times 10 \mathrm{~mm}$ steel plates were prepared for each column as the end plates. During the specimen fabrication, a steel plate was welded to the bottom of the steel tube. The SSC was poured into the steel tube, and a poker vibrator was employed for compaction. A plastic film and an aluminum sheet were used to seal the surface of the concrete to simulate the real curing environment. After the concrete was set, the aluminum sheet and the plastic film were removed, and the other steel plate was welded to the top of the specimen. During the process, the welding quality was checked, and the geometric centers of the plate and steel tube were aligned.

Table 1

Components of the SSC and the measured strength (Yu et al., [17])

\begin{tabular}{|c|c|c|c|c|c|c|c|c|}
\hline \multirow{2}{*}{$\begin{array}{l}\text { Particle size of steel } \\
\text { slag / mm }\end{array}$} & \multicolumn{4}{|c|}{ Material usage $/ \mathrm{kg} \cdot \mathrm{m}^{-3}$} & \multirow{2}{*}{$\begin{array}{l}\text { Cube compressive } \\
\text { strength / } \mathrm{MPa}\end{array}$} & \multirow{2}{*}{$\begin{array}{c}\text { Expansion rate } E_{\mathrm{x}} \\
\qquad / 10^{-4}\end{array}$} & \multirow{2}{*}{$\begin{array}{l}\text { Elastic modulus } \\
\qquad / 10^{4} \mathrm{MPa}\end{array}$} & \multirow{2}{*}{ Poisson's ratio } \\
\hline & Water & Portland cement & Graded gravel & Steel slag & & & & \\
\hline $1.18 \sim 2.36(100 \%)$ & 201 & 365 & 961 & 621 & 34.29 & -3.5 & 3.61 & 0.242 \\
\hline $\begin{array}{c}0.15 \sim 0.3(75 \%) \\
0.3 \sim 0.6(25 \%)\end{array}$ & 201 & 365 & 961 & 621 & 21.85 & 2.8 & 2.74 & 0.222 \\
\hline
\end{tabular}

Table 2

Design parameters of the specimens

\begin{tabular}{cccccc}
\hline Specimen & $L / \mathrm{mm}$ & $D / \mathrm{mm}$ & $t / \mathrm{mm}$ & $D / t$ & $E_{\mathrm{x}} / 10^{-4}$ \\
\hline SCA1-1 & 500 & 140 & 2.08 & 67.3 & 2.8 \\
SCA2-2 & 500 & 140 & 2.08 & 67.3 & -3.5 \\
SCA3-1 & 500 & 140 & 3.63 & 38.6 & 2.8 \\
SCA4-2 & 500 & 140 & 3.63 & 38.6 & -3.5 \\
SCA5-1 & 500 & 140 & 4.22 & 33.2 & 2.8 \\
SCA6-2 & 500 & 140 & 4.22 & 33.2 & -3.5 \\
\hline
\end{tabular}

Note: $D, t, L$, and $E_{\mathrm{x}}$ are the measured steel tube outside diameter, thickness, length, and the expansion rate of SSC, respectively.
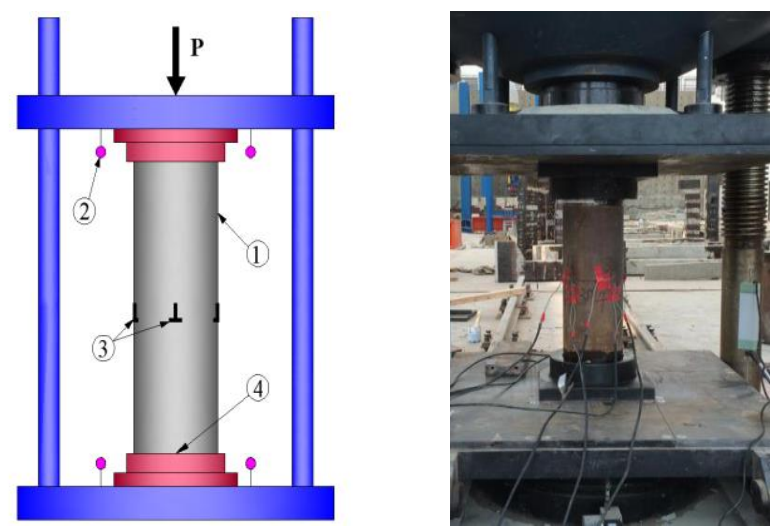

(1) Specimen (2) LVDT (3) Strain gauge (4) Steel column cap

Fig. 1 Test set-up and measuring points arrangement

As shown in Fig. 1, a $5000 \mathrm{kN}$ hydraulic compression testing machine was used for applying the monotonic static loads. The axial and circumferential strains at the mid-height of each steel tube were measured at four positions around the perimeter by eight strain gauges. Four LVDTs (Linear Variable Differential Transformers) were used to monitor the movements of the end steel plates, and two LVDTs were placed at a side. The steel column caps were set at both ends of the column, and the compression test was carried out directly on the hydraulic compression testing machine. The preloading process was conducted before the formal test to ensure that the test setup was correctly installed, and the measuring instruments run well.

Firstly, the load-controlled scheme (step loading approach) was carried out. Each loading level was estimated to be $1 / 15$ of the column theoretical load capacity and kept constant for 5 minutes. Then, the displacementcontrolled loading scheme (step loading controlled by displacement) was used when the load reached to approximately $85 \%$ of the theoretical load capacity. When the columns were closed to the damage or the load began to decline, the specimen was slowly and continuously loaded until the columns failed or the load reduced to $85 \%$ of the column ultimate load capacity.

\section{Experimental results and analysis}

\subsection{Failure progress and modes}

Several experimental phenomena, such as the gradual drop of the rust, the local yielding of steel tube, the slight sound of the inner SSC crushing, and the local buckling, were noticed in the tests. The failure process of the specimens experienced three stages as elasticity, elastoplasticity and plasticity. In the early and middle experimental stages, the specimen's appearance remained intact, which was similar to the conventional CFST short columns. As the load increased to $70 \% \sim 80 \%$ of the ultimate strength, the rust fell off gradually and tubes started to yield. The slight sound of the SSC crushing could be occasionally heard in this stage. As the load reached $90 \%$ $95 \%$ of the ultimate strength, local buckling appeared near the ends or center of the columns. Finally, the shear deformation dominated the failure of the SSSCFST short columns with the low confinement effect coefficient under axial compression, see Fig. 2 (a), (b) and (d), while the outward local buckling dominated the failure of the SSSCFST short columns with the high confinement effect coefficient under axial compression, as shown in Fig. 2 (c), (e) and (f) Generally, more local buckling occurred in the columns with higher expansion rate of SSC. For example, one local buckling appeared in the SCA4-2 column, while three local buckling appeared in the SCA3-1 column. Moreover, the buckling was more serious as the column with smaller diameter-thickness ratio, as shown in Fig. 2 (a) and (e)

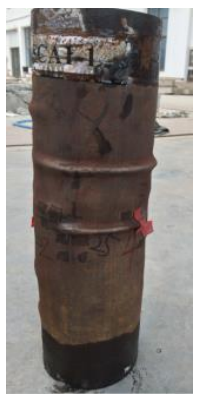

(a) SCA1-1

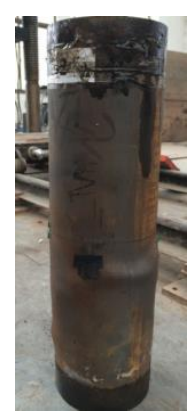

(d) SCA4-2

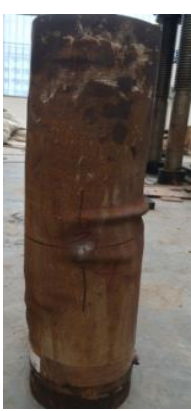

(b) SCA2-2

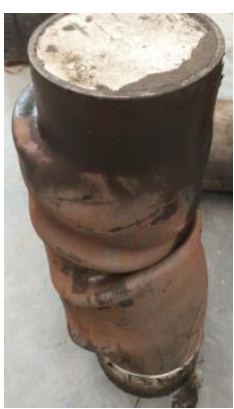

(e) SCA5-1

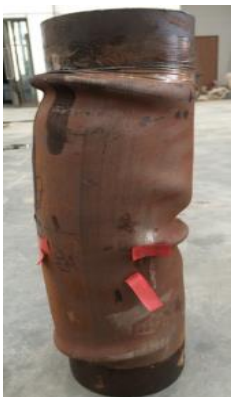

(c) SCA3-1

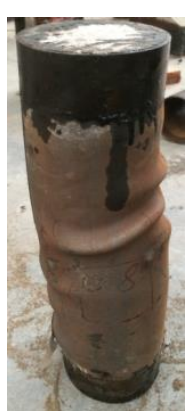

(f) SCA6-2
Fig. 2 The failure modes of the SSSCFST short columns 


\subsection{Ultimate load capacity analysis}

Fig. 3 shows the influences of two parameters, i.e., $E_{\mathrm{x}}$ and $D / t$, on the ultimate load capacity of the axially loaded SSSCFST short columns. The incremental range of load capacity $\left(N_{\mathrm{u}} / N_{0}\right)$ [17] of the axially loaded columns was plotted in Fig. 3(a). In which, $N_{\mathrm{u}}$ represents the ultimate load capacity, $N_{0}$ denotes the nominal compressive strength, $N_{0}=f_{\mathrm{y}} A_{\mathrm{s}}+f_{\mathrm{c}} A_{\mathrm{c}}, f_{\mathrm{y}}$ is the yield strength of the steel tube, $f_{\mathrm{c}}$ is the compressive strength of the core concrete, $A_{\mathrm{s}}$ and $A_{\mathrm{c}}$ represent the cross-sectional area of the steel tube and core concrete, respectively. As can be seen from the comparison, the average incremental range of load capacity increases by $11.8 \%$ with the expansion rate rising from $-3.5 \times 10^{-4}$ to $2.8 \times 10^{-4}$. The impact of the $E_{\mathrm{x}}$ on the incremental range of load capacity is more significant when the $D / t$ is larger. For instance, the improvement of the incremental range of load capacity of the column with the $D / t=33.2$ is $10.5 \%$. In contrast, the improvement of the incremental range of load capacity of the column with the $D / t=67.3$ is $14.4 \%$.

According to the results plotted in Fig. 3(b), the ultimate load capacity of the column decreases almost linearly as the $D / t$ increases. Taking the columns with the $E_{\mathrm{x}}=2.8 \times 10^{-4}$ as examples, when the $D / t$ increases from 38.6 to 67.3 , the ultimate load capacity decreases by $38.5 \%$. The reason is that the steel tube with a higher $D / t$ has a weaker constraint on the infill, which decreases the member load capacity.

In consequence, the increase in the $E_{\mathrm{x}}$ or the reduction in the $D / t$ in a reasonable range can effectively enhance the ultimate load capacity of the axially loaded SSSCFST short columns.

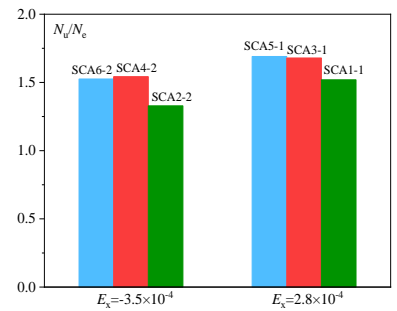

(a) Expansion rate of SSC

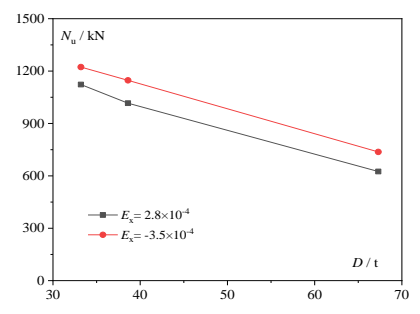

(b) Diameter-thickness ratio
Fig. 3 Influence of the variable parameters on the load capacity

\subsection{Load-displacement analysis}

Fig. 4 depicts the influence of the two studied parameters on the load-displacement $(N-\Delta)$ curves of the axially loaded SSSCFST short columns. In which, $N$ represents the axial load, $\Delta$ denotes the axial displacement of the short columns. As can be seen from the figure that the load-displacement curves of the two series columns have the similar trends. Initially, the load-displacement curves of the columns increase approximately linearly and the slope of the load-displacement curves decreases with the increase of the $D / t$, as shown in Fig. 4(a). This may come from that when the diameter of the outer steel tube remains unchanged, increasing the $D / t$ will correspondingly reduce the initial combined stiffness of the column section. At this stage, the slope of the load-displacement curves decreases with the increase of the $E_{\mathrm{x}}$, as shown in Fig. 4(b). This is mainly because in this study, the strength and elastic modulus of the SSC with the high $E_{\mathrm{x}}$ are smaller than those of the SSC with the low $E_{\mathrm{x}}$, resulting in the low initial stiffness of the columns with high $E_{\mathrm{x}}$. With the increase of load, the load-displacement curves deviate from linear growth, and the obvious inflection points appear on the curves. The increase in the $D / t$ decreases the yield strength of the columns. Subsequently, the load capacity grows slowly, while the axial displacement develops faster. The ultimate axial displacement of the columns decreases as the $D / t$ increases. The reason is that the decrease of the $D / t$ correspondingly weakens the confinement effect of the outer steel tube on the core SSC. Comparatively, the effect of the $E_{\mathrm{x}}$ on the ultimate axial displacement is not significant.
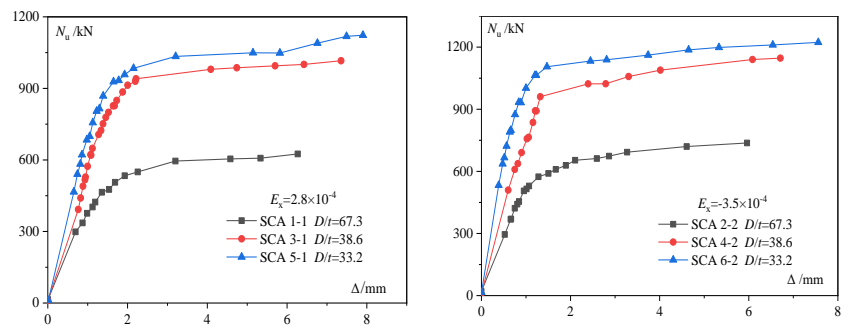

(a) Diameter-thickness ratio
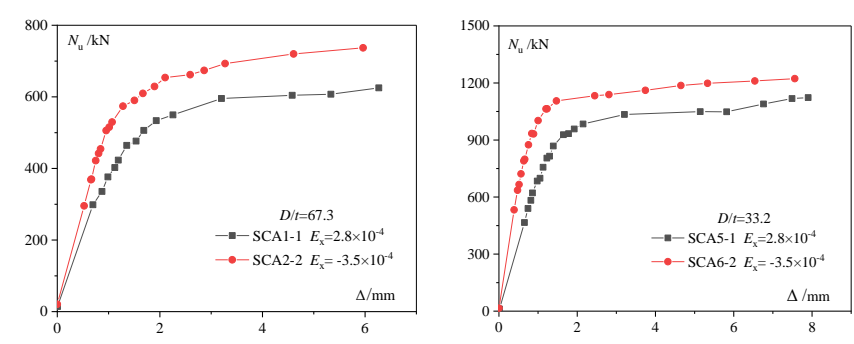

(b) Expansion rate of SSC

Fig. 4 Influence of the variable parameters on the load-displacement curves

\subsection{Ultimate strain analysis}

Fig. 5 describes the influences of the $E_{\mathrm{x}}$ and $D / t$ on the column ultimate strains. In which, $\varepsilon_{\text {alim }}$ and $\varepsilon_{\text {clim }}$ represent the ultimate axial and circumferential strains at the mid-height of the steel tube, respectively. In terms of the overall trend, the ultimate axial strain $\varepsilon_{\text {alim }}$ is larger than the circumferential strain $\varepsilon_{\text {clim }}$. As shown in Fig.5(a), with the increase of the $E_{\mathrm{x}}$, the column ultimate axial and circumferential strains increase. Taking the specimens SCA1-1 and SCA2-2 as examples, the ultimate axial strain and circumferential strain of the column increase by $5.0 \%$ and $18.8 \%$ when the $E_{\mathrm{x}}$ increases from $-3.5 \times 10^{-4}$ to $2.8 \times 10^{-4}$. This indicates that the increase of the $E_{\times}$ has a more obvious effect on the increase of the circumferential strain of the columns. Increasing the $D / t$ will decrease the ultimate axial strain and circumferential strain of the columns, as demonstrated in Fig. 5(b). Taking the specimens SCA3-1 and SCA5-1 as examples, the ultimate axial strain and circumferential strain of the column decrease by $15.0 \%$ and $9.9 \%$ when the $D / t$ of the specimen increases from 38.6 to 67.3 . This is mainly because the increase of the $D / t$ weakens the confinement effect of the steel tube on the core SSC, reduces the ultimate bearing capacity, and correspondingly decreases the ultimate strains of the columns.

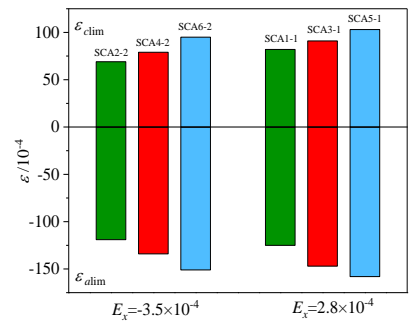

(a) Expansion rate of SSC

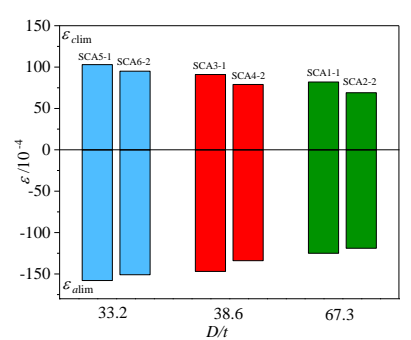

(b) Diameter-thickness ratio
Fig. 5 Influence of the variable parameters on the column ultimate strains

\section{Design recommendations}

Scholars have conducted numerous theoretical and experimental researches on the CFST and have compiled corresponding design specifications or codes for the CFST, such as the British Standard BS EN1994-2 [18], Hong Kong Code CoPHK [19], Australian Standard AS5100-2017 [20], and Chinese Specification DBJ/T 13-51-2010 [21]. In this section, the calculated results according to these specifications are compared to the SSSCFST short columns experimental data to verify the accuracy and applicability of the design approaches for the proposed structural form.

\subsection{BS EN1994-2}

BS EN1994-2 [18] was published under the authority of the Standards Policy and Strategy Committee. This code presents a design formula for the CFST members, which considers the composite action between the various elements forming the cross section. In this standard, the structural steel section should be universal section of grade S235 to S460 steel, a characteristic 28-day cube strength of concrete $f_{\text {cu }}$ should be not less than $20 \mathrm{MPa}$ for the CFST members. In addition, the maximum value $D / t$ of such cross-section parameters should be not exceed than $90\left(235 / f_{y}\right)$. The axial compressive bearing capacity of the CFST members can be calculated as follows.

$N_{\mathrm{u}}=\eta_{\mathrm{ao}} A_{\mathrm{s}} f_{\mathrm{y}}+A_{\mathrm{c}} f_{\mathrm{cu}}\left(1+\eta_{\mathrm{co}} \frac{t}{D} \frac{f_{\mathrm{y}}}{f_{\mathrm{cu}}}\right)$ 
$\eta_{\mathrm{ao}}=0.25(3+2 \bar{\lambda})$

$\bar{\lambda}=\sqrt{\frac{A_{\mathrm{s}} f_{\mathrm{y}}+A_{\mathrm{c}} f_{\mathrm{cu}}}{N_{\mathrm{cr}}}}$

$$
N_{\mathrm{cr}}=\pi^{2}(E I)_{\mathrm{e}} / L_{\mathrm{e}}^{2}
$$

where, $N_{\mathrm{u}}$ represents the nominal section capacity of the circular CFST columns, $A_{\mathrm{s}}$ and $A_{\mathrm{c}}$ are the cross-sectional area of the steel tube and concrete, respectively. $\eta_{\text {a }}$ and $\eta_{\text {co }}$ are the calculated coefficients when the axial compression CFST column section is circular. $\bar{\lambda}$ is the relative slenderness, and $N_{\text {cr }}$ is the elastic critical load, $(E I)_{\mathrm{e}}$ and $L_{\mathrm{e}}$ represent the effective flexural stiffness and length, respectively.

\subsection{CoPHK-2011}

CoPHK-2011 [19] was prepared by the Buildings Departments. The design formula of the compressive bearing capacity assuming the full section yielding is adopted for the composite structures. In another word, when the axial compression reaches the member ultimate design load, the steel yields and the infilled concrete reaches the ultimate compressive bearing capacity, simultaneously. The design formula in this code applied to CFST columns with steel yield strengths between $235 \mathrm{MPa}$ to $460 \mathrm{MPa}$ and normal weight concrete of strength classes $\mathrm{C} 25$ to $\mathrm{C} 60$. The relative slenderness ratio $\bar{\lambda}$ of the axially loaded CFST columns is not more than 0.5 . The plastic resistance may be calculated from the following expressions.

$N_{\mathrm{u}}=\eta_{\mathrm{ao}} A_{\mathrm{s}} f_{\mathrm{y}}+0.53 A_{\mathrm{c}} f_{\mathrm{cu}}\left(1+\eta_{\mathrm{co}} \frac{t}{D} \frac{f_{\mathrm{y}}}{0.8 f_{\mathrm{cu}}}\right)$

$\bar{\lambda}=\sqrt{\frac{\eta_{\mathrm{ao}} A_{\mathrm{s}} f_{\mathrm{y}}+0.8 A_{\mathrm{c}} f_{\mathrm{cu}}\left(1+\eta_{\mathrm{co}} \frac{t}{D} \frac{f_{\mathrm{y}}}{0.8 f_{\mathrm{cu}}}\right)}{N_{\mathrm{cr}}}}$

In this code, the values and calculations of the variables are the same as those in the British Standard BS EN1994-2 [18].

\subsection{AS5100 - 2017}

AS5100-2017 [20] was issued by Committee BD-090, Bridge Design. Considering the composite action between various components, this code provides the design formulas for predicting the circular and rectangular CFST columns, respectively. The design formula in this code applied to the circular CFST columns with a maximum yield stress of $690 \mathrm{MPa}$, and the relative slenderness $\bar{\lambda}$ is not greater than 0.5 . The ultimate nominal section capacity of the circular CFST columns under axial load can be calculated as follows.

$N_{\mathrm{u}}=\phi A_{\mathrm{s}} \eta_{\mathrm{ao}} f_{\mathrm{y}}+\phi_{\mathrm{c}} A_{\mathrm{c}} f_{\mathrm{cu}}\left(1+\frac{\eta_{\mathrm{co}} t f_{\mathrm{y}}}{D f_{\mathrm{cu}}}\right)$

$\bar{\lambda}=\sqrt{\frac{A_{\mathrm{s}} \eta_{\mathrm{ao}} f_{\mathrm{y}}+A_{\mathrm{c}} f_{\mathrm{cu}}\left(1+\frac{\eta_{\mathrm{co}} t f_{\mathrm{y}}}{D f_{\mathrm{cu}}}\right)}{N_{\mathrm{cr}}}}$

where, $\phi$ and $\phi_{c}$ denote the capacity factor for the steel and concrete, $\phi=0.9$ and $\phi_{\mathrm{c}}=0.65$.

\section{4. $D B J / T 13-51-2010$}

DBJ/T13-51-2010 [21] was issued by the Department of Housing and Urban-Rural of the Fujian Province. The design formula of the compressive bearing capacity using the unified theory was developed for the CFST members based on numerous experimental studies and numerical simulation analysis. In this specification, the strength grade of core concrete is not less than $\mathrm{C} 30$ and the water-cement ratio should not be greater than 0.45 . The concrete and steel are considered as a composite material. The material properties of the composite material are given in this specification. The axial compressive bearing capacity of the CFST members can be determined as follows.

$N \leq N_{\mathrm{u}}=f_{\mathrm{sc}} A_{\mathrm{sc}}$

$f_{\mathrm{sc}}=(1.14+1.02 \xi) f_{\mathrm{c}}$

where $f_{\mathrm{sc}}$ denotes the design value of compressive strength of the CFST members, $A_{\mathrm{sc}}$ stands for the section area of the CFST members, $\xi$ represents the confinement effect coefficient, $\xi=f_{\mathrm{y}} A_{\mathrm{s}} / f_{\mathrm{c}} A_{\mathrm{c}}$.

\subsection{Comparison of the theoretical and experimental results}

The comparisons between the theoretically calculated values $N_{\mathrm{ci}}$ from the above CFST design provisions and the experimental results $N_{\mathrm{u}}$ are summarized in Table 3. As shown in the table, the Australian Standard AS5100-2017 and Hong Kong Code CoPHK-2011 underestimate the load capacity of the SSSCFST short columns, from which the results are averagely $60.4 \%$ and $65.3 \%$, respectively, less than the experimental results. In contrast, the results from the British Specification BS EN1994-2 and the Chinese Specification DBJ/T13-51-2010 are relatively accurate with $15.1 \%$ and $29.9 \%$ differences, compared to the experimental results. Therefore, it is recommended to use BS EN1994-2 and DBJ/T13-51-2010 to calculate the ultimate load capacity of the axially loaded SSSCFST short columns.

Table 3

Contrast between the theoretical calculated and experimental results of columns

\begin{tabular}{|c|c|c|c|c|c|c|c|c|c|}
\hline \multirow[b]{2}{*}{ Specimen number } & \multirow{2}{*}{$\frac{\text { Experimental data }}{N_{\mathrm{u}} / \mathrm{kN}}$} & \multicolumn{2}{|c|}{ BS EN1994-2 [18] } & \multicolumn{2}{|c|}{ CoPHK-2011 [19] } & \multicolumn{2}{|c|}{ AS5100 - 2017 [20] } & \multicolumn{2}{|c|}{ DBJ/T13-51-2010 [21] } \\
\hline & & $N_{\mathrm{cl}} / \mathrm{kN}$ & $N_{\mathrm{u}} / N_{\mathrm{c} 1}$ & $N_{\mathrm{c} 2} / \mathrm{kN}$ & $N_{\mathrm{u}} / N_{\mathrm{c} 2}$ & $N_{\mathrm{c} 3} / \mathrm{kN}$ & $N_{\mathrm{u}} / N_{\mathrm{c} 3}$ & $N_{\mathrm{c} 4} / \mathrm{kN}$ & $N_{\mathrm{u}} / N_{\mathrm{c} 4}$ \\
\hline SCA1-1 & 625 & 551 & 1.13 & 366 & 1.71 & 388 & 1.61 & 479 & 1.30 \\
\hline SCA2-2 & 737 & 725 & 1.02 & 459 & 1.60 & 502 & 1.47 & 653 & 1.13 \\
\hline SCA3-1 & 1016 & 829 & 1.23 & 603 & 1.68 & 604 & 1.68 & 718 & 1.42 \\
\hline SCA4-2 & 1147 & 991 & 1.16 & 691 & 1.66 & 712 & 1.61 & 893 & 1.28 \\
\hline SCA5-1 & 1123 & 913 & 1.23 & 676 & 1.66 & 670 & 1.68 & 799 & 1.41 \\
\hline SCA6-2 & 1223 & 1071 & 1.14 & 762 & 1.60 & 776 & 1.58 & 974 & 1.26 \\
\hline Average value & - & - & 1.151 & - & 1.653 & - & 1.604 & - & 1.299 \\
\hline Mean square error & - & - & 0.071 & - & 0.038 & & 0.071 & - & 0.097 \\
\hline
\end{tabular}

\section{Finite element analysis}

\subsection{Material modeling}

The stress-strain relation of the steel tube is plotted in Fig. 6 [22]. The curve is linear initially, the plastic flow initiates after. Beyond the certain strain, the linearly hardening commences, and the stiffness is assumed to be zero after the ultimate strain is reached. The detailed relation can be 


$$
\sigma_{\mathrm{s}}=\left\{\begin{array}{l}
E_{\mathrm{s}} \varepsilon_{\mathrm{s}} \quad 0 \leq \varepsilon_{\mathrm{s}} \leq \varepsilon_{\mathrm{s} 1} \\
f_{\mathrm{sy}} \quad \varepsilon_{\mathrm{s} 1} \leq \varepsilon_{\mathrm{s}} \leq \varepsilon_{\mathrm{s} 2} \\
f_{\mathrm{sy}}+E_{s t}\left(\varepsilon_{\mathrm{s}}-\varepsilon_{\mathrm{s} 2}\right) \quad \varepsilon_{\mathrm{s} 2} \leq \varepsilon_{\mathrm{s}} \leq \varepsilon_{\mathrm{s} 3} \\
f_{\mathrm{su}} \quad \varepsilon_{\mathrm{s}} \geq \varepsilon_{\mathrm{s} 3}
\end{array}\right.
$$

where, $\sigma_{\mathrm{s}}, \varepsilon_{\mathrm{s}}$ are the equivalent stress and strain, $\varepsilon_{\mathrm{s} 1}$ represents the yield strain, $\varepsilon_{\mathrm{s} 2}=12 \varepsilon_{\mathrm{s} 1}$ is the hardening strain of steel tube, $\varepsilon_{\mathrm{s} 3}=120 \varepsilon_{\mathrm{s} 1}$ is the strain for the ultimate strength, $E_{\mathrm{s}}$ is the Young's modulus of steel tube, $E_{\mathrm{st}}=\xi E_{\mathrm{s}}$ is the strengthening Yong's modulus of steel tube, $\xi=1 / 216$ is the strengthening coefficient, $f_{\mathrm{sy}}$ is the yield strength of the steel tube, $f_{\mathrm{su}}=1.5 f_{\mathrm{sy}}$ is the ultimate strength of steel tube.

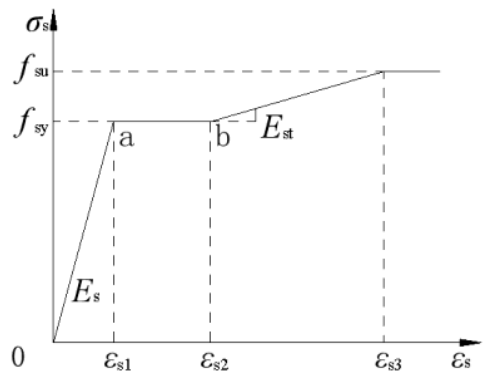

Fig. 6 The stress-strain relation of the steel tube

The existing studies show that [23] the characteristics of the stress-strain relationship curves of the core concrete of CFST are mainly related to the confinement effect coefficient $\xi$, which are mainly shown as the greater the value of $\xi$, the stronger the confinement action provided by the steel tube on the core concrete during the stress process. With the increase of deformation, the declining section of the stress-strain curve of the core concrete appears relatively late. Similar to the ordinary CFST, the strength of the SSSCFST can also be improved by the confinement action of steel tube on the core SSC. Therefore, the stress-strain relationship model of the core SSC of SSSCFST proposed in this study is modified on the basis of the stress-stress relationship model of the core concrete of CFST, as shown below.

$\sigma_{\mathrm{c}}=\sigma_{\mathrm{po}}\left[A \frac{\varepsilon_{\mathrm{c}}}{\varepsilon_{\mathrm{po}}}-B\left(\frac{\varepsilon_{\mathrm{c}}}{\varepsilon_{\mathrm{po}}}\right)^{2}\right]$

$$
\varepsilon_{\mathrm{c}} \leq \varepsilon_{\mathrm{po}}
$$

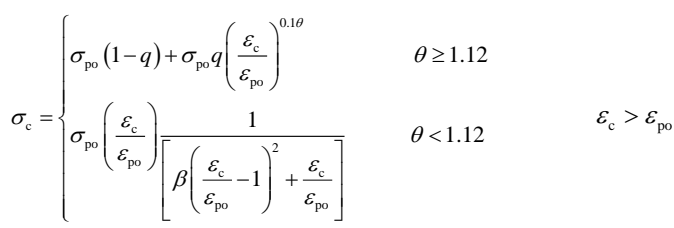

where, $\sigma_{\mathrm{c}}, \varepsilon_{\mathrm{c}}$ are the equivalent stress and strain of the axially loaded SSC, respectively. $\sigma_{\mathrm{po}}, \varepsilon_{\mathrm{po}}$ represent the uniaxial peak compressive stress and strain of the SSC. $\beta$ is the parameter, which was fitted by the regression analysis of the test data, $A=2-T, B=1-T, T=0.1 \theta^{0.745}, q=T /(0.2+0.1 \theta)$. $\theta\left(\theta=f_{\mathrm{y}} A_{\mathrm{s}} / f_{\mathrm{co}} A_{\mathrm{c}}\right)$ is the nominal confinement effect coefficient. $f_{\mathrm{co}}=0.67 f_{\mathrm{cu}}$ is the compressive strength of the SSC.

In view of the proposed model's adaptability and simplicity of calculation, the nominal confinement effect coefficient $\theta$ is not modified in this study and it is directly calculated by the formula of the confinement effect coefficient of CFST $\xi$. However, on the basis of experimental research, considering the influence of the self-stress between the steel tube and SSC, the strength enhancement coefficient of SSC $\mu$ is introduced, the key parameters of the stress-strain relationship model of the core concrete affected by the SSC, such as the uniaxial peak compressive stress $\sigma_{\mathrm{po}}$ and strain $\varepsilon_{\mathrm{po}}$ of the SSC, and the parameter $\beta$, are modified respectively, as shown below.

$\mu=1+K \frac{\sigma_{0}}{f_{\text {co }}}$

In which, $\sigma_{0}$ stands for the self-stress between the steel tube and SSC, as shown in Eq.(17), $K=3.0$ is the lateral confined coefficient determined by
$\sigma_{0}=E_{\mathrm{c}}\left(E_{\mathrm{x}}-E_{\mathrm{xr}}\right)$

where, $E_{\mathrm{c}}$ represents the Young's modulus of the SSC, $E_{\mathrm{xr}}$ denotes the confined expansion rate of the SSC [24].

$$
\begin{aligned}
& \sigma_{\mathrm{po}}=\mu f_{\mathrm{co}}\left[1.194+\left(\frac{13}{\mu f_{\mathrm{co}}}\right)^{0.45}\left(-0.07485 \theta^{2}+0.5789 \theta\right)\right] \\
& \varepsilon_{\mathrm{po}}=\varepsilon_{\mathrm{co}}+\left[1400+800 \frac{\mu f_{\mathrm{co}}-20}{20}\right] \theta^{0.2}
\end{aligned}
$$

$\beta=\left(2.36 \times 10^{-6}\right)^{\left[0.25+(\theta-0.5)^{7}\right]}\left(\mu f_{\text {co }}\right)^{2} \times 5 \times 10^{-4}$

In which, $\varepsilon_{\mathrm{co}}$ is the strain corresponding to the uniaxial compressive strength of the SSC, $\varepsilon_{\mathrm{co}}=1300+14.93 \mu f_{\mathrm{co}}$.

\subsection{Finite Element Model}

\subsubsection{Elements and contact interaction}

S4R and C3D8R are employed to mesh the steel tube and SSC. Simpson integral of 9 integral points is adopted to accurately simulate member element. The sensitivity investigation indicates that both the outer steel tube and core SSC are meshed with $20 \mathrm{~mm}$ element size. The typical FE model is depicted in Fig. 7.

Surface-to-surface contact interaction is adopted between the steel tube and SSC. Hard contact is designated as the interaction between two surfaces, the tangential behavior of contact surfaces is determined by the Coulomb friction model and the friction coefficient is set as 0.3 . Shell-to-solid-coupling contact interaction is employed between the steel tube and the loading plates.

\subsubsection{Load and boundary conditions}

Displacement controlled scheme is adopted in FE model analysis. Fixed constraints are applied to the bottom of the column and the constraints in the $\mathrm{X}$ and $\mathrm{Y}$ directions are applied to the top of the column, so as to ensure that the specimens only produce displacement in the $\mathrm{Z}$ direction. The incremental iteration approach is employed and the initial, minimum, and maximum increment are set as $0.01,1 \times 10^{-5}$ and 10 , respectively.

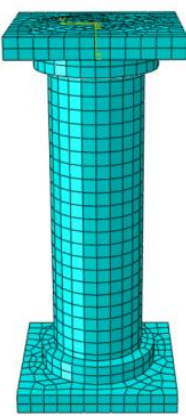

(a) Integral model

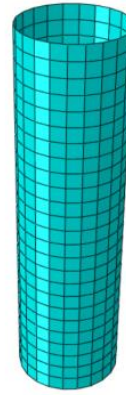

(b) Steel tube

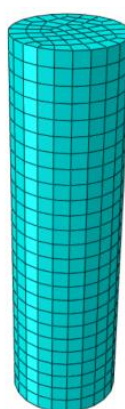

(c) SSC
Fig. 7 Typical FE model for the SSSCFST short column

\subsection{Verification of FE model}

The comparison of typical failure mode of the specimens is shown in Fig. 8. As can be seen from the figure, the most obvious failure characteristics of the specimens are the expansion of SSC in the middle and the bulge of the steel tube, which are basically consistent with the FE simulation results. For the test results, most of the specimens show uneven bulge and local buckling. After reaching the peak bearing capacity, the local buckling phenomenon is more obvious due to continuing loading. The reason for the small deviation between the FE simulation results and the experimental results is that the initial defects of the steel tube and SSC are not taken into account in the FE simulation. The calculation is stopped due to the convergence problem near the peak point, and the specimen's declining behavior after the peak point is 
not considered. Therefore, the failure modes simulated by the FE model don't exhibit obvious buckling phenomenon. In addition, test data of load capacity and ultimate compressive strain of the axially loaded SSSCFST short columns are compared with FE prediction results, as shown in Table 4. In which, $N_{\mathrm{c}}$ and $\varepsilon_{\text {cau }}$ represent the predicted values of the load capacity and ultimate compressive strain. $\varepsilon_{\text {au }}$ denotes the measured test data of the ultimate compressive strain. Obviously, the FE model established above can well predict the load capacity and ultimate compressive strain of the SSSCFST short columns under axial load. The average ratio of the $N_{\mathrm{c}} / N_{\mathrm{u}}$ and $\varepsilon_{\text {cau }} / \varepsilon_{\text {au }}$ are 1.051 and 0.948 , respectively, and the standard deviation of the $N_{\mathrm{c}} / N_{\mathrm{u}}$ and $\varepsilon_{\text {cau }} / \varepsilon_{\text {au }}$ are 0.0691 and 0.0156 , respectively.

Moreover, Fig. 9 depicts the comparisons between the measured stress-strain relation curves and the stress-strain curves predicted by FE analysis. In which, $\sigma_{\mathrm{a}}$ represents the compressive stress, $\varepsilon_{\mathrm{a}}$ denotes the axial compressive strain. The proposed FE model reasonably predicts the stress-strain response of the SSSCFST short columns under axial load. The change trends of the predicted curves and the measured curves are basically consistent. The estimated axial stiffness agrees well with the measured axial stiffness.
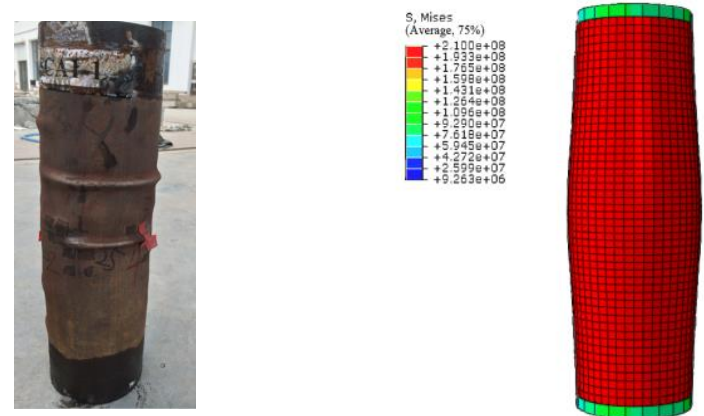

Fig. 8 Comparison between the column failure mode

Table 4

Comparisons between the measured test data and FE model predicted values

\begin{tabular}{|c|c|c|c|c|c|c|c|c|}
\hline Specimen & $D / \mathrm{t}$ & $E_{\mathrm{x}} / 10^{-4}$ & $N_{\mathrm{u}} / \mathrm{kN}$ & $N_{\mathrm{c}} / \mathrm{kN}$ & $\varepsilon_{\text {au }}$ & $\varepsilon_{\mathrm{cau}}$ & $N_{\mathrm{c}} / N_{\mathrm{u}}$ & $\varepsilon_{\mathrm{cau}} / \varepsilon_{\mathrm{au}}$ \\
\hline SCA1-1 & \multirow{2}{*}{67.30} & 2.8 & 625 & 711 & -0.0125 & -0.0117 & 1.138 & 0.936 \\
\hline SCA2-2 & & -3.5 & 737 & 841 & -0.0119 & -0.0113 & 1.141 & 0.950 \\
\hline SCA3-1 & \multirow{2}{*}{38.56} & 2.8 & 1016 & 1035 & -0.0147 & -0.0139 & 1.019 & 0.946 \\
\hline SCA4-2 & & -3.5 & 1147 & 1141 & -0.0134 & -0.0131 & 0.995 & 0.978 \\
\hline SCA5-1 & \multirow{2}{*}{33.17} & 2.8 & 1123 & 1129 & -0.0158 & -0.0148 & 1.005 & 0.937 \\
\hline SCA6-2 & & -3.5 & 1223 & 1231 & -0.0151 & -0.0142 & 1.007 & 0.940 \\
\hline Average value & - & - & - & - & - & - & 1.051 & 0.948 \\
\hline Mean square error & - & - & - & - & - & - & 0.0691 & 0.0156 \\
\hline
\end{tabular}

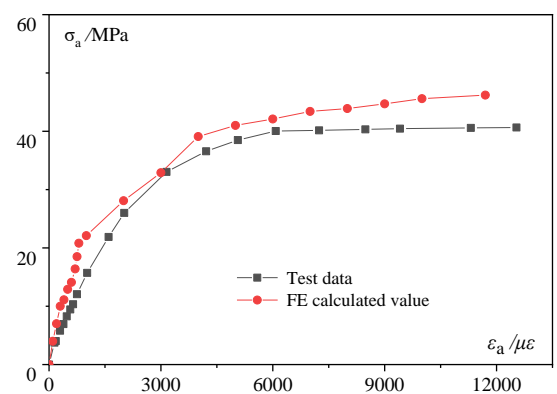

(a) SCA1-1

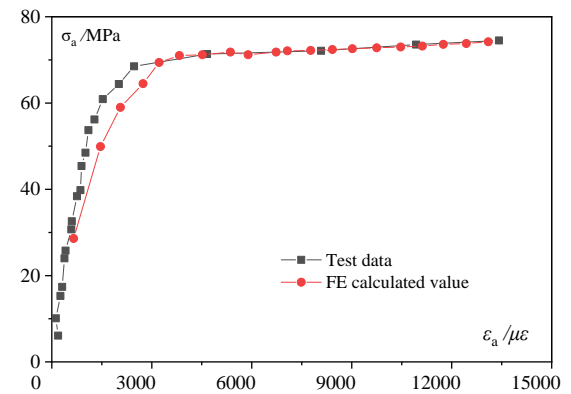

(d) SCA4-2

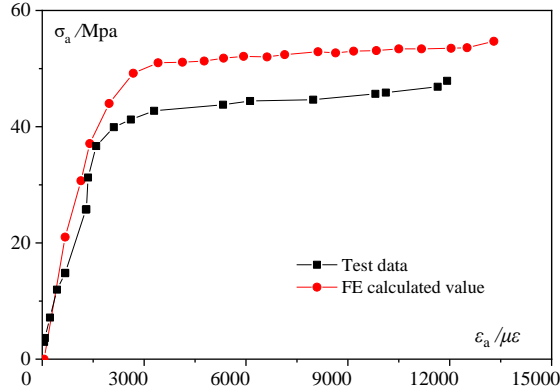

(b) SCA2-2

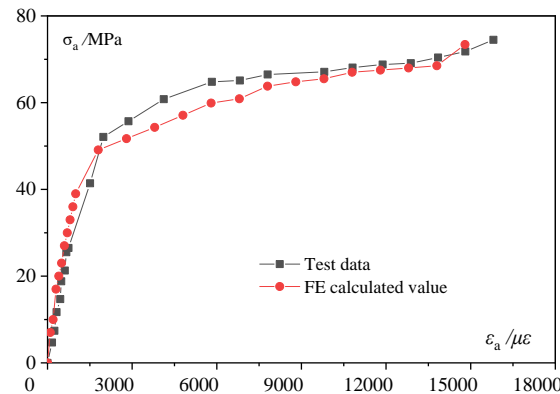

(e) SCA5-1

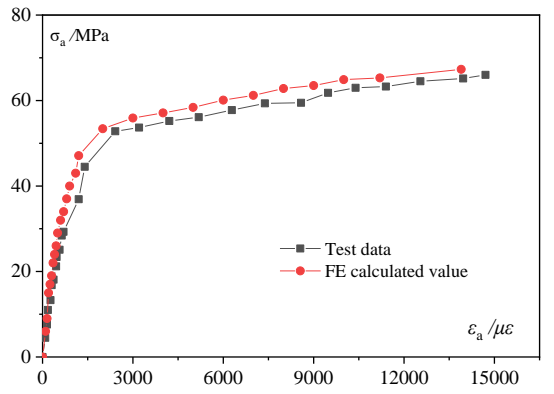

(c) SCA3-1

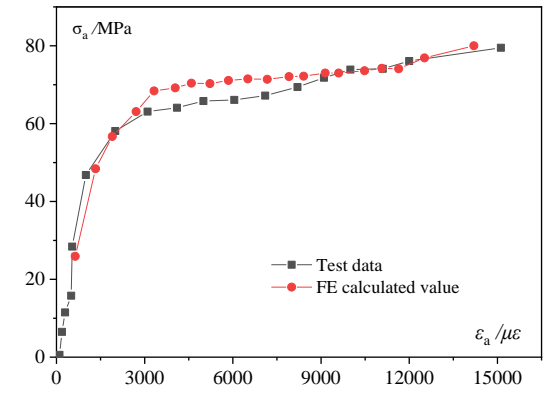

(f) SCA6-2

Fig. 9 Comparisons between the measured stress-strain curves and stress-strain curves predicted by FE analysis

\subsection{Parametric studies}

In this section, the parametric studies are conducted to examine the impacts of variation in the steel ratio $\alpha$ (when $t<<r, \alpha=A_{\mathrm{s}} / A_{\mathrm{c}} \approx 2 t / r$ ), the yield strength of steel tube $f_{\mathrm{y}}$, and the core concrete strength grade $f_{\mathrm{c}}$ on the member's mechanical behaviors. Specimen SCA 3-1 is employed as the comparative reference. Stress-strain $\left(\sigma_{\mathrm{a}}-\varepsilon_{\mathrm{a}}\right)$ relation curves of the axially loaded SSSCFST short columns with different steel ratios, yield strength of the steel tube, and core concrete strength grades are depicted in Fig. 10, Fig. 11 and Fig. 12.

As depicted in Fig. 10, the increase of steel ratio $\alpha$ will increase the initial stiffness, prolong the elastic stage of the specimen. This may come from that the confining effect of the steel tube on the SSC enhances with the increase of steel ratio. As the load increases, the columns come into the elastoplastic stage, and the stress of the SSSCFST short columns grows slowly, while the strain develops rapidly. The strain development rate decreases with the increase of the steel ratio.

As depicted in Fig. 11, initially the specimens are in the elastic stage and the stress-strain relation curves of the specimens with different steel yield strength $f_{\mathrm{y}}$ are basically identical. With the increase of load, the stress-strain relation curves deviate from linear growth, and the SSSCFST short columns enter elastoplastic stage. Subsequently, the specimens yield and the obvious inflection points appear on the stress-strain relation curves. After yielding, the stress increases slowly while the strain develops rapidly. 
The impact of the strength grade of core concrete $f_{\mathrm{c}}$ on the stress-strain relation curves of the SSSCFST short columns subjected to axial load is described in Fig. 12. Apparently, the stress-strain relation curves of the specimens with different strength grades of core concrete are basically consistent initially. As the load increases, the stress-strain relation curves increase non-linearly. As the load further increases, the obvious inflection points appear and the yield stress of the specimens increases as the strength grade of core concrete $f_{\mathrm{c}}$ enhances.

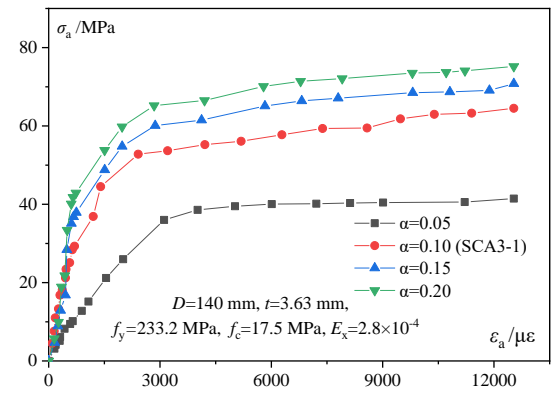

Fig. 10 Effect of $\alpha$ on the stress-strain relation curve

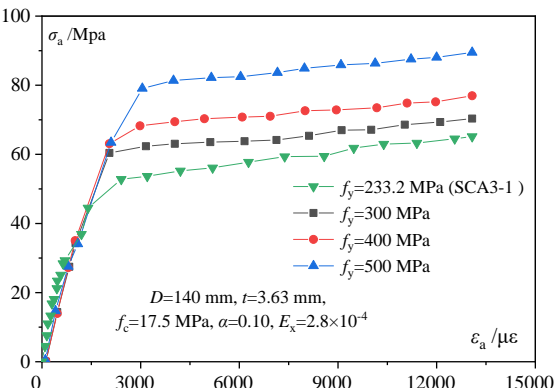

Fig. 11 Effect of $f_{y}$ on the stress-strain relation curve

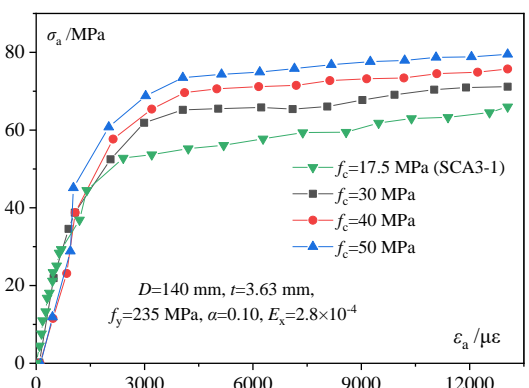

Fig. 12 Effect of $f_{\mathrm{c}}$ on the stress-strain relation curve

\section{Conclusions}

The mechanical performance of the six axially loaded SSSCFST short columns is investigated and the accuracy of the conventional design approaches for the innovative composite members is evaluated. The following conclusions can be drawn.

(1)The SSSCFST short columns with the low confinement effect coefficient under axial load are damaged by shear deformation, while the outward local buckling dominates the failure of the axially loaded SSSCFST short columns with the high confinement effect coefficient.

(2)The ultimate load capacity decreases as the diameter-thickness ratio increases. The incremental range of load capacity can be improved by enhancing the expansion rate. The member ultimate axial and circumferential strains increase with the increase of the expansion rate while they decrease with the increase of the diameter-thickness ratio.

(3) The load-displacement curves of the six SSSCFST short columns demonstrate similar trends, including three stages as elasticity, elastic-plasticity and plasticity. The ultimate axial displacement of the columns decreases with the increase of the diameter-thickness ratio while the

\section{References}

[1] Furlani E., Tonello G. and Maschio S., "Recycling of steel slag and glass cullet from energy saving lamps by fast firing production of ceramics", Waste Management, 30(8), $1714-1719,2010$

[2] Jiang Y., Ling T.C., Shi C. and Pan S.Y., "Characteristics of steel slags and their use in cement and concrete-a review", Resources Conservation and Recycling, 136, 187-197, 2018.

[3] Yu X., Tao Z., Song T.Y. and Pan Z., "Performance of concrete made with steel slag and waste glass", Construction and Building Materials, 114, 737-746, 2016.

[4] Yu F., Yao C., Hu Y., Fang Y., Niu K., and Xiang G. S. "Axial compressive behavior of self-stressing steel slag aggregate concrete filled steel tubular columns with bond-slip damage", Advanced Steel Construction, 16(1), 13-19, 2020.

[5] Liu J. and Wang D., "Influence of steel slag-silica fume composite mineral admixture on the properties of concrete", Powder Technology, 320, 230-238, 2017.

[6] Anastasiou E., Filikas K.G. and Stefanidou M., "Utilization of fine recycled aggregates in concrete with fly ash and steel slag", Construction and Building Materials, 50(50), 154-161, 2014

[7] Morone M., Costa G., Polettini A., Pomi R. and Baciocchi R., "Valorization of steel slag by a combined carbonation and granulation treatment", Minerals Engineering, 59, 82-90, 2014.

[8] Wang Q., Wang D. and Zhuang S., "The soundness of steel slag with different free $\mathrm{CaO}$ and MgO contents", Construction and Building Materials, 151, 138-146, 2017.

[9] Han L.H., Li W. and Bjorhovde R.., "Developments and advanced applications of concrete-filled steel tubular (CFST) structures: members", Journal of Constructional Steel Research, 100, 211-228, 2014.

[10] Yang C., Yu Z. X., Sun Y.P., Zhao L. and Zhao H., "Axial residual capacity of circular concrete-filled steel tube columns considering local buckling", Advanced Steel Construction, 14(3), 496-513, 2018.

[11] Yu F., Wang X.L., Yang Z. and Xu L., "Stress-strain relationship of shrinkage compensating steel-slag concrete", Journal of Building Materials, 20(4), 527-534, 2017. effect of expansion rate on the ultimate axial displacement is not significant.

(4) The paper evaluates the prescriptive methods in designing the SSSCFST columns under axial load. The comparisons between the test data and calculation results of the specification design formulas demonstrate that the British Specification BS EN1994-2 and Chinese Specification DBJ/T13-51-2010 can provide satisfactory results for the member load capacity.

(5) A validated FE model for the axially loaded SSSCFST short columns is adopted to perform parametric studies to broaden the available experimental results about their mechanical behaviors.

\section{Acknowledgements}

This work was sponsored by National Natural Science Foundation of China (No. 51578001, 51878002, 52078001), Outstanding Youth Fund of Anhui Province (No. 2008085J29), Natural Science Research Project of Anhui Universities (No. KJ2020A0234, KJ2020A0261), and the University Synergy Innovation Program of Anhui Province (No. GXXT-2019-005).

[12] Beggas D. and Zeghiche J., "The use of slag stone concrete to improve the therma performance of light steel buildings", Sustainable Cities and Society, 6(1), 22-26, 2013.

[13] Zeghiche N.F.J., "Numerical analysis of cold-formed steel welded tube filled with concrete made of crystallized slag aggregate", International Journal of Applied Electromagnetics and Mechanics, 16(1), 112, 2014.

[14] Ferhoune N., "Experimental behaviour of cold-formed steel welded tube filled with concrete made of crushed crystallized slag subjected to eccentric load", Thin-Walled Structures, 80(1), 159-166, 2014

[15] GB/T228.1-2010, Metallic Materials-Tensile Testing - Part 1: Method of Test at Room Temperature, China Architecture and Building Press, Beijing, China, 2010.

[16] GB50010-2010, Code for design of concrete structures, China Architecture and Building Press, Beijing, China, 2010

[17] Yu F., Fang Y., Zhang Y., Xu L. and Bai R.., "Mechanical behavior of self-stressing steel slag aggregate concrete filled steel tubular stub columns", Structural concrete, 21(1), 1597-1611, 2020.

[18] BS EN1994-2, Eurocode 4 - Design of composite steel and concrete structures - Part2: General rules and rules for bridges, British Standards Institution, London, British, 2005.

[19] CoPHK-2011, Code of practice for the structural use of steel, Buildings Department, Hong Kong SAR Government, Hong Kong, 2011.

[20] AS5100.6-2017, Australia Standard bridge design, Part 6: Steel and composite construction, Committee BD-090, Bridge Design, Sydney, Australia, 2017.

[21] DBJ/T13-51-2010, Technical specification for concrete-filled steel tubular structures, Fujian: Department of Housing and Urban-Rural of the Fujian Province, Fuzhou, China 2010.

[22] Ding F.X. and Yu Z.W., "Theoretical analysis of mechanical properties of concrete filled tubular steel stub columns", Engineering Mechanics, 22(1), 175-181, 2005.

[23] Han L.H., "Concrete Filled Steel Tubular Structure-theory and Application", Science Press, Beijing, China, 2016.

[24] Xu L., "Experimental study and theoretical analysis on static performance of the steel slag concrete-filled circular steel tube", Master Thesis, Anhui University of Technology, 2015. 